\title{
The influence of family social capital on the employment intention of Medical College Students
}

\author{
Xingshan $\mathrm{Li}$ \\ Luohe Mdeical College, Luohe 462002 China \\ aemail:604141388@qq.com
}

Keywords: Family Social Capital; Poor Medical College Students; Employment Intention

\begin{abstract}
Family support is to improve medical backing to poor college students find jobs successfully, therefore, it is of great significance to analyze the influence of family social capital on the employment intention of medical college students, so as to choose the appropriate methods to accumulate and use the family social capital effectively, and to improve the employment ability.
\end{abstract}

\section{Introduction}

With the development of economy and society in China, the investment of education has been further increased. The number of college students has increased year by year, and the number of poor students will increase accordingly. According to incomplete statistics, about $15 \%$ of our country's university college students in the reading belongs to the poor college students. According to the national ministry of education figures, released by the end of last century, the poor students in colleges and universities and obtains respectively $15 \%$ and $12 \%$ of the total number of college students. And according to the China youth daily survey statistics, the proportion of poor students in the national college students now almost $25 \%$, which obtains the proportion reached $10 \% \sim 15 \%$. Therefore, there will be millions poor college students need jobs in our country each year, they become the vulnerable groups in the university students' employment can not be neglected. Strengthening employment work, guides them to set up the correct choosing profession idea, develop good employment psychology, realize self value of life, has become the important subject of college students' employment work in common colleges and universities[1].

Poor medical students because of the particularity of specialty, the employment problem has attracted many attentions of the academic circles. These factors in addition to the poor medical students knowledge structure, ability of clinical practice, etc of human capital, social capital also plays an important role. The article mainly analyzes the family social capital influence on medical poor college students employment intention, and puts forward Suggestions for the accumulation, use of family social capital.

\section{The influence of family social capital factors on medical students' Employment Intention}

Social capital refers to the relationship between individuals or groups Social networks and the resulting trust, reciprocal norms, which is the resources that people place in the social structure. Social capital is a concept first used by sociologists, the earliest use of the concept of social capital is Granovetter, but the academic circles has been on what is social capital has not yet formed a unified concept, different scholars from the fields of research paradigm, make a different definition of the concept of social capital. To sum up, these concepts have formed three research levels, such as micro, meso and macro. social capital as distinguished from physical capital and human capital, personal resources in social structure. It provides convenience for the actors in the structure, including norms, trust, network and other forms[2]. Family social capital is an important part of social capital, for this article, mainly refers to the poor medical college students embedded in the family social network, the use of resources for the purpose of achieving the purpose of Medical College Students. Poor college students of medicine family social capital depends on the family's social and economic status and family structure, the internal and external network it through successful collective action, the combination of resources and exchange to create value, to follow is 
a kind of reciprocity, the collaborative adaptation mechanism of trust, and only when the "relationship" and "network" then be instrumental utilization, it became a resource. Poor college students of medicine, in general, family social capital is mainly composed of parents' education level, professional level, family income, family expectations and so on factors, which directly influence the employment intention.

A large number of studies have shown that when people use of social capital in search of work, often can match the work more effectively. Beijing Normal University of China's employment problem research group in 2002 of 14 provinces and cities nationwide 5990 college graduates survey, an important reason for the implementation of work in social relations in second place

(Guangwei $\mathrm{Hu}, 2003$ ). Although the above said in the survey of "social relations" is not equivalent to social capital, but can be seen from the survey results, both in concept in the real results, one of the important factors of social capital is still affecting the employment of college graduates.

The employment intention is the individual in the choice of occupation demonstrated the process of preliminary, shallow employment demand, it has certain instability and fuzziness, may choose the actual behavior of employment become, may also not become subsided and the actual behavior of employment choice[3]. The value of family social capital has a direct impact on the value judgment and employment intention of medical college students in poverty, and the two variables of parents' education level and family socioeconomic status are analyzed. (1) The level of education and values of parents, to a certain extent, affect the medical students' professional philosophy, employment intentions. This effect is mainly reflected in two aspects, one is the words and deeds of parents, life experience has a certain impact on the employment of medical college students. According to the survey found that the family members of a high degree of education, members of the school of medicine, poor medical students may be more willing to study medicine, employment is more objective, rational. The second is reflected in the participation of parents in the process of employment of medical students in poverty, or to discuss the decision-making, or the use of authority and the way to help them get the ideal career. This shows that the choice of career is not only a personal decision, but also a collective decision of the whole family based on the social and economic status. (2) Family socioeconomic status directly affects the cost of employment of poor medical students, to a certain extent, will limit the poor medical college students' job hunting behavior. The survey found that poor medical college students in the employment process, due to the urgent hopes to change their employment and family status, often such as working in big city hospital, good working environment and working conditions, social status, self realization and so on to consider these as important goals, to achieve this by the value orientation of employment benefit will restrict employment aspirations.

\section{Poor medical students to accumulate and use countermeasures of family social capital}

\section{Changing ideas, play a positive role of family social capital.}

Supply and demand of human capital structure is not consistent with education screening function failure. Education is regarded as a social talents "filter", through the effective signals of education, ability can be filtered. However, in the real labor market, the information between job seekers and employers is asymmetric, employers do not really understand the ability and level of job seekers. In order to reduce the employment risk caused by asymmetric information, job seekers must provide information to their employers to show their ability. The information includes the applicant's primary factors, such as home, gender, family background and other family social capital, but also includes the post job seekers, such as education, professional ability of human capital. The former referred to as the identity of the employment, the latter is called the employment of signal. When the employer is unable to confirm the true ability of the applicant, the applicant will be identified through the identification and ability[4]. The degree of education can become one of the signals that distinguish the individual human capital and its ability effectively.

Transaction costs caused by employment competition. Social activities is people, groups and 
groups, between the organization and the organization and social exchange, or social transaction, these transactions are the costs, and an important aspect of social capital is that it is a trust mechanism, the social capital to provide the necessary trust can greatly reduce the transaction the two sides of the transaction costs in the social competition. From a practical point of view, the employment of college students is more and more competition. First, with the deepening of the popularization of higher education, college enrollment continues to expand, the number of graduates is more and more, more and more intense competition for jobs, The second is due to the industry, occupation and unfair treatment, but also because the concept of employment, employment and social interests, college graduates choose the big city and high welfare, high returns of state-owned units in droves, especially state-owned monopoly enterprises and institutions $^{[4]}$. Everyone in the pursuit of high-quality jobs, can be suitable for college students employment is bound to become a scarce resource, competition is inevitable.

Information cost caused by imperfect human resource market. The social existence employment amount of information is large and complex, the members of the society for all the information may not fully grasp or may not easily grasp completely, to collect information on social costs, while social capital can reduce the cost of information search. If the employees themselves can especially be able to grasp the very complete employment information in a relatively low cost or relatively simple way, then the social capital will lose the space to play a role in the employment activities. In reality, it is impossible for one to master all the useful information. Although China's labor market is gradually improving, college students employment market information sources and transfer mode gradually diversification and modernization, newspapers, television, Internet and other media, recruitment, talent market and other places are more and more college students as information access tools used. However, information asymmetry is a common problem in the labor market. At the present stage of our country, because the human resources market is still in the start-up period, can not form a unified national market system is not perfect, information asymmetry phenomenon, coupled with the current system factors, such as urban-rural segmentation, industry segmentation and separatist state departments, the transfer of employment information for college graduates human resources market appear too smooth and the efficiency is not high in the embarrassing situation. Therefore, the lack of openness and availability for the exchange of information between the employer and the students, labor supply and demand a large amount of information exchange is still a non institutionalized or semi institutionalized stage, college students employment information is asymmetric[4]. Therefore, in order to obtain valuable job information, college graduates must pay a certain amount of information transaction costs, so as to shorten the time limit for job hunting.

In the context of the current labor market is not perfect, the position of supply and demand information is not enough, the impact of family social capital on the employment intention of medical college students, the mechanism and the root cause is obvious. If the poor medical students can use the social capital of the family to achieve successful employment under the premise of fair competition, understandable, but if the family social capital, excessive generalization to all aspects of employment, the allocation of scarce resources in human society, the relationship between natural factors as the basis, will inevitably result in intergenerational mobility of identity constraints, human resource allocation problems caused by the dislocation of social discontent. Therefore, accumulation and utilization of family social capital should be carried out in the rules of the market economy, such as transactions right trade and trade power for money, the loss of social justice on the family's social capital should be put an end to illegal occupation.

Guide families to lower expectations, create a relaxed and harmonious family atmosphere.

According to the survey, medical poor students carrying higher expectations of the society and the family often desire to excel over others, not far behind, with excessive self-esteem, vulnerable to the formation of both self-esteem and self-esteem, both strong and fragile dual personality[5]. At present, the overall employment situation is grim in the social background, medical poor students may have a higher degree of ideal occupation orientation in employment intention, occupation choice utilitarian tendency, which is very unfavorable for the realization of successful employment. Poor medical college students have the kind of employment intention, and most of them come from 
the high expectations of the family. Family members should pay more attention to the changes of the social demands for medical talents, and give them a proper understanding, consideration and care, and strive to create a relaxed and harmonious family atmosphere. At the same time, parents should be inspirational education of medical students, family education, tolerance education, guide its focus on communication with outside, to dispel loneliness, learn to get along with others.

The establishment of the government, colleges and universities, the employer cooperation mechanism, smooth employment information channels.

Government support is the guarantee to promote the employment of medical college students. The government should improve the employment support policies, strengthen supervision responsibilities and other aspects to guide medical students to accurately grasp the occupation orientation, clear the direction of employment at the grassroots level, to avoid accomplish nothing. School support is the basis for promoting the employment of medical college students. Schools should build information exchange platform, to carry out targeted employment guidance and other aspects of efforts, so that poor medical students get full employment information. Employing unit is the basis of promoting the employment of medical students. Employers want to attend the meeting of supply and demand and recruitment, and in the recruitment process in the same conditions as far as possible to tilt to the poor medical students, and strive to achieve effective docking with the school as a unit. In short, the government, colleges and universities, employers should work together to open channels of employment information, and constantly improve the employment rate of medical college students.

Participate in practical activities, and strive to expand their social capital stock.

Part of the poor medical college students due to economic poverty and prone to inferiority, anxiety, self closure and a series of psychological problems, so that it can not deal with interpersonal relationships. The poor except for medical students to face the economic poverty, more measures should be taken to try to accumulate social capital itself, in a timely manner to understand the employment dynamic, clear the advantages and disadvantages of its own, rationally choose, find the most suitable for their jobs. Family basically depends on parents' socioeconomic status, social capital has the congenital, generally do not change because of the differences between the individual. However, the poor college students in the school during the medical use of spare time to do part-time jobs, to participate in various community activities, can also use the opportunity to practice, continue to accumulate experience and social experience, expand the scope of social network, accumulate more social capital. In the family life, the medical impoverished college students should learn to care for family members and relatives and friends, and actively take the initiative to keep in touch with friends and family, strengthen communication, so as to continuously expand their social capital stock.

In short, family social capital is an important factor that affects the employment intention of medical college students, it can promote the employment information flow and improve the success rate of employment. However, the family social capital to really play a role, is the need to constantly adjust the medical impoverished college students' knowledge structure, enhance the ability of clinical practice, only to be promoted at the same time in the quality of the individual, family and social capital can play a greater role.

\section{Acknowledgement}

In this paper, the research was sponsored by the College Graduates Employment Entrepreneurship Research project in Henan Province In 2016 (Project No. YB2016110), Henan Soft Science Research project(Project No. 172400410517).

\section{References}

[1] Qiufang Xiao. Local college students employment problems and countermeasures. Education Exploration[J].2010,8:142-143 
[2] Jie Zhuang. A review of the theory of social capital. Development Forum[J].2003,1:79-80

[3] Xuewen Zhao. Research on the influence of family social capital on College Students' Employment Intention[D].2015 ,East China Normal University

[4] Maoxiong Zheng. The mechanism of family social capital affects college students' employment. Education Research Monthly[J].2012,4:8-12

[5] Xueping XU. Countermeasures of psychological help on medical impoverished undergraduates. Chinese medicine modern distance education of China[J]. 2016,14（1）:30-32 